NASCIMENTO, Flávia Brito do. A construção da ideia de patrimônio moderno no Brasil: Valorações e práticas dos anos 1940 aos 2000. Thésis, Rio de Janeiro, v. 5, n. 9, p. 85-106, nov. 2020

data de submissão: 05/10/2020 data de aceite: $12 / 11 / 2020$

\section{A construção da ideia de patrimônio moderno no Brasil: Valorações e práticas dos anos 1940 aos 2000} Flávia Brito do Nascimento

Flávia Brito do NASCIMENTO é Doutora pela FAU USP; flaviabn@usp.br

\section{Resumo}

O presente artigo pretende discutir a construção da ideia de patrimônio moderno no Brasil a partir das ações do Iphan - Instituto do Patrimônio Histórico e Artístico Nacional, do Inepac - Instituto Estadual do Patrimônio cultural e do Condephaat - Conselho Estadual do Patrimônio Histórico, Arqueológico, Artístico e Turístico. Problematizando as primeiras ações de tombamento e os entrelaçamentos entre historiografia e patrimônio, pretende-se colocar em debate os crivos teóricos e as práticas discursivas do patrimônio no Brasil dos anos 1940 até os tombamentos icônicos, como os da obra completa de Oscar Niemeyer em 2007, por ocasião de seu centenário. Pretende-se debater as suas atribuições de valor e consagrações das individualidades arquitetônicas.

Palavras-chave: arquitetura moderna, tombamentos, IPHAN.

\begin{abstract}
This article aims to discuss the construction of the idea of modern heritage in Brazil based on the actions of the Institute of National Historical and Artistic Heritage (Iphan). Problematizing the first attempts at listing historic buildings and sites, as well as the intertwining of historiography and heritage, it seeks to promote a debate on the theoretical lenses and discursive practices of heritage in Brazil, focusing on a period that spans from the $1940 \mathrm{~s}$ until landmark listings in the 2000s - such as that of the complete works of Oscar Niemeyer in 2007, the year of his 100th birthday. In addition, it seeks to discuss the notions of value and the widespread acclaim of individual architectural expressions.
\end{abstract}

Keywords: modern architecture; listings; IPHAN.

\section{Resumen}

El presente artículo pretende discutir la construcción de la idea de patrimonio moderno en Brasil a partir de las acciones del Iphan Instituto do Patrimônio Histórico e Artístico Nacional (Instituto del Patrimonio Histórico y Artístico Nacional). Cuestionándose las primeras acciones declaratorias y los entrelazamientos entre historiografía y patrimonio, se pretende poner en discusión los tamices teóricos y las prácticas discursivas del patrimonio en Brasil, en los años 1940 hasta las declaraciones como patrimonio cultural icónicas como las de la obra completa de Oscar Niemeyer en 2007, con ocasión de su centenario. Se pretende debatir sus atribuciones de valor y consagraciones de las individualidades arquitectónicas.

Palabras-clave: arquitectura moderna; declaración del patrimonio cultural; IPHAN.

\section{Introdução}

A construção da ideia de "patrimônio moderno" no Brasil finca raízes na tradição do movimento moderno que, desde o Estado Novo, passou a protago- 
nizar ações de preservação por meio do instituto do tombamento. A arquitetura moderna, legitimada pelos seus protagonistas, figurou na listagem de bens tombados desde muito cedo, com muitas das obras recém-inauguradas. Desde então, o patrimônio nacional e suas atribuições de valor estão imiscuídos na trama da arquitetura moderna. O patrimônio moderno construiu-se no Brasil a partir dos comprometimentos dos arquitetos modernos com a preservação, cujas práticas seletivas percorreram caminhos argumentativos próprios, focados na arquitetura de matriz corbusiana e servindo como argumentos de afirmação historiográfica. A arquitetura moderna e sua afirmação no campo cultural e arquitetônico adquirira em 1930 status de batalha durante a passagem de Costa pela direção da ENBA - Escola Nacional de Belas Artes, à qual se seguiu a contenda com José Marianno Filho. A partir daí, passos substanciais foram dados em favor da consolidação do grupo moderno, com protagonismo costiano na prancheta e nas letras. A tomada de lugar no campo do patrimônio histórico e artístico nacional será grande fronteira conquistada pelos arquitetos modernos, conquista esta inseparável da valoração da arquitetura moderna.

Se nas ações do Iphan - Instituto do Patrimônio Histórico e Artístico Nacional - existe íntima relação entre a arquitetura que se considerou relevante de salvaguarda e a escrita da história dessa mesma arquitetura, na proteção da arquitetura moderna tais relações tornaram-se operativas. Os arquitetos modernos lançaram mão do tombamento como recurso de afirmação da arquitetura defendida como garantia da materialidade e prova de originalidade, não só às gerações futuras mas às ameaças do presente. A preocupação com a autenticidade e integridade das obras do movimento moderno, os critérios de seleção fundamentados na historiografia e nos saberes técnicos dos arquitetos e a valoração das obras monumentais foram referência nos tombamentos do Iphan. Os arquitetos das instituições de patrimônio no papel de herdeiros da tradição garantiam a integridade dos vestígios materiais da narrativa arquitetônica nacional e os tombamentos produziam a história. A valoração do movimento moderno no Iphan e pelos órgãos estaduais a partir dos anos 1970, tendeu à perpetuação das práticas da ortodoxia patrimonial, seguindo o conceito de Marly Rodrigues (2000). A hegemonia construída pela ação inicial do Iphan foi tornada memória social e fixou na lembrança dada a imagem tradicional de patrimônio (MOTTA, 2000).

As bases de preservação nacional que se construíram ainda nos anos 1940 deram o lastro teórico para as 
preservações futuras. A memória do moderno no Brasil se firmará nos anos 1980, no momento de crise de sua linguagem. A partir da década de 1990, quando a arquitetura moderna entra na agenda de preocupações patrimoniais em nível internacional, a construção do moderno excepcional e monumental se seguirá mesmo nas ações regionais. Obras icônicas, exaltação do passado heroico, personificação dos grandes nomes e fetichização das edificações serão reforçadas pelo mundo patrimonial, às expensas dos muitos movimentos em favor da ampliação de conhecimento e da construção de visões críticas e múltiplas de suas realizações.

\section{As primeiras preservações da arquitetura moderna pelo IPHAN, anos 1940-1960}

Como já foi dito por diversos autores, em termos cronológicos e estilísticos, a grande maioria dos tombamentos do Iphan até os anos 1970 recaiu sobre edificações e cidades do período colonial formando um conjunto homogêneo (RUBINO, 1996; CHUVA, 2009) As exceções à esse grupo de tombamentos saltam aos olhos, sendo as mais evidentes as das obras do movimento moderno. Algumas delas eram recém-construídas ou sequer estavam finalizadas à época da proteção jurídica.

Ainda que no Iphan os critérios artísticos tenham prevalecido sobre os históricos nos atos de valoração (RUBINO, 1996), na história do pensamento e das políticas patrimoniais a combinação entre fatores históricos e artísticos foi sempre importante. Disso decorre a surpresa inicial com o ineditismo dos primeiros tombamentos do moderno realizados no Brasil. Os critérios de ancianidade seguem relevantes em muitos países onde a necessidade de distanciamento temporal da época da construção das edificações é condição para a salvaguarda, o que gera empecilhos à proteção de bens do século XX. A construção da memória da arquitetura moderna internacional iniciou-se contemporaneamente à inauguração das obras, protagonizada também pelos próprios autores que se empenharam na criação de fundações que guardassem sua memória, como Le Corbusier e Frank Lloyd Wright, e pela historiografia que exaltou as realizações do moderno (NASCIMENTO, 2016). No Brasil, a proteção jurídica dos bens modernos atendeu aos objetivos dos arquitetos modernos que assumiram postos no órgão oficial de preservação, construíram as políticas e escreveram a história da arquitetura. 
Os tombamentos do Iphan de bens culturais de expressão moderna dividem-se, grosso modo, em dois momentos: o primeiro vai de 1947 até 1967, e o segundo de 1983 ao presente. A Igreja da Pampulha, de Oscar Niemeyer, abre o primeiro bloco de seis tombamentos realizados durante a gestão de Rodrigo Melo Franco de Andrade, que se encerra em 1967 com o reconhecimento da Catedral Metropolitana de Brasília. Um intervalo de quase 20 anos separa este último do tombamento da sede da Associação Brasileira de Imprensa, ABI, no Rio de Janeiro, em 1983, ao qual se seguiu outra leva de reconhecimentos da arquitetura moderna, quando a instituição, a arquitetura brasileira e patrimônio estavam em outro momento, no contexto da redemocratização política.

Nos primeiros tombamentos do Iphan de bens imóveis do movimento moderno a relação com a história da arquitetura foi pragmática. Preponderaram as inscrições de edificações indispensáveis à "trama narrativa" que estavam ameaçadas de inconclusão ou mutilação, garantindo-se sua permanência como provas materiais do moderno nacional. A justificativa para o reconhecimento precoce adivinha do fato de tais obras já serem monumentos que os destinariam a ser inscritos, "mais cedo ou mais tarde, nos Livros do Tombo", como declarou Lucio Costa ao defender a proteção à Igreja da Pampulha. Compõem este lote de obras do primeiro momento a Igreja de São Francisco de Assis, da Pampulha, o edifício do MESP, a Estação de Hidroaviões, o Catetinho, o Parque do Flamengo e a Catedral de Brasília.

De modo geral, conforme pesquisa nos processos de tombamento do Iphan, estas proteções legais foram guiadas pela assertiva da arquitetura considerada verdadeira e na busca por sua consagração por meio da articulação entre historiografia e proteção jurídica, utilizada nos casos considerados extremos de perda eminente. Como nos demais processos da instituição deste período, os reconhecimentos partiram dos técnicos e não esconderam a clareza de propósitos da salvaguarda dos exemplares mais importantes do momento contemporâneo. Ministério da Educação e Cultura, Igreja de São Francisco de Assis e Estação de Hidroaviões foram declarados patrimônio nacional em razão de seus valores artísticos excepcionais, assim eleitos pelo grupo. Se no Ministério a intenção era a comemoração do feito da arquitetura nacional, marco inaugural da nova tradição edilícia, na igreja e na estação utilizava-se o recurso jurídico para a manutenção das realizações importantes do moderno ameaçadas de descaracterização. (IPHAN, Processo 
de tombamento n.0373-T-47, Igreja de São Francisco de Assis; Processo de tombamento n. 0375-T-48, Edifício na Rua da Imprensa, 16)

Por serem tão recentes à época do tombamento e suas argumentações estarem tão intimamente ligadas à afirmação do projeto de arquitetura em curso, tais ações de salvaguarda são exemplos didáticos dos processos que envolvem a atribuição de valor no patrimônio cultural. Demonstram como são projetos socialmente construídos e atendem a propósitos particulares, no caso brasileiro daqueles anos, de construção da nacionalidade. A materialização da nação por meio da arquitetura perpassou as ações da cultura do Estado Novo e prosseguiu nos anos seguintes, quando os saberes técnicos ainda ditavam a eleição do patrimônio da nação. A partir do tombamento do Catetinho, em 1959, os pedidos de proteção de edificações modernas chegam ao Iphan assinados por prefeitos ou governadores interessados na continuidade física e simbólica do seu legado político (IPHAN, Processo de tombamento Edifício conhecido como RP-1 ou "Catetinho" 0594-T-59). Encontram a instituição ensimesmada, com práticas rotineiras, e pouco afeita às sugestões ao patrimônio nacional, uma tarefa que afinal, por décadas, coube exclusivamente aos técnicos, não obstante o "tombamento voluntário" estar previsto no Decreto-lei n. 25 de 1937. Como o Catetinho, a Catedral de Brasília e o Aterro do Flamengo eram também expressões do moderno nacional com características de excepcionalidade ou de monumentalidade e encontraram guarida no Iphan. O que parece ser mais importante é que sua relevância como tal é argumentada por agentes de fora da instituição de patrimônio cultural. Leigos e eruditos legitimam as obras ao pedirem e assentirem com a necessidade dos tombamentos. Ou seja, os valores do moderno já estavam consagrados.

O professor e conselheiro do Iphan Paulo Santos, em seu parecer sobre o Aterro do Flamengo, nos dá dimensão do lastro do moderno e do processo de construção de sua memória nos anos 1960, que se evidenciará nas décadas seguintes. A aceitação para o tombamento de objeto inusitado e a argumentação em favor da paisagem são indícios das novidades, mas a justificativa do tombamento pela natureza grandiosa e excepcional da obra de Affonso Eduardo Reidy e Burle Marx cristaliza as práticas (IPHAN, Processo de tombamento, n. 0748-T-64).

Se os objetos e problemas patrimoniais começam a mudar, os valores da arquitetura moderna foram exaltados na condição de patrimônio nacional serão cor- 
roborados pelos processos de enraizamento do movimento conscientemente efetuados nos anos 1940 e 1950 , dos quais as ações do Iphan fazem parte. A emergência de novas expressões arquitetônicas nos anos 1980 e os questionamentos dos "rumos" da arquitetura brasileira estiveram constantemente acompanhados das lembranças e realizações dos modernos, agora exaltados como mestres. Monumentalidade e excepcionalidade serão frequentemente listados nos atributos das obras modernas que serão objeto de patrimonialização nos anos seguintes, sobretudo a partir dos anos 1980, sendo justificativa e justificando o conquistado lugar de memória.

\section{Anos 1980: tombamento e construção de memória}

Durante o período de redemocratização na década de 1980, as reivindicações por memória urbana e o alargamento do campo da preservação são percebidas na atuação dos órgãos de preservação (RODRIGUES, 2001; MOTTA, 2000). Como em muitos outros países, os anos 1980 foram cruciais para a construção da memória da arquitetura moderna. Respondendo às duras críticas recebidas, organizações sociais, entidades de classe, preservacionistas e órgãos de preservação se levantaram em defesa do patrimônio do século XX num sentido mais largo, ou especificamente, do patrimônio do movimento moderno. A criação, em 1989 da ONG Docomomo - Documentation and Conservation of the Modern Movement - na Holanda, rapidamente agregou muitos interessados ao redor do mundo que, reunidos em congressos bianuais, defendem o seu legado. No caso brasileiro, entretanto, a crítica ao movimento moderno ficou difusa, mal-elaborada. Passou-se ao estágio da construção de memória dos grandes mestres da arquitetura sem que o processo de crítica tivesse gerado debates públicos. A preservação moderna neste período foi feita na chave da celebração, com muitas publicações e algumas proteções legais. O grande interesse pela arquitetura moderna é atestado, por exemplo, pelo sucesso do Docomomo-Brasil que já organizou inúmeros encontros nacionais e internacionais, sendo responsável por estimular uma vasta produção sobre o assunto. O envelhecimento, a mudança de usos e os problemas de manutenção atingiam diversas obras construídas em meados do século $\mathrm{XX}$. Em muitos casos mobilizavam-se os argumentos da inadequação e da falência do movimento moderno.

O patrimônio cultural estava no vértice das ações e debates sobre o urbano daqueles anos. As disputas por memórias e narrativas de identidade nacional coloca- 
ram o passado e a preexistência física das cidades no campo de disputas que pressionaram por ações para além daquelas impostas pela chamada "ortodoxia do patrimônio". Dentro do Iphan e em órgãos estaduais e municipais, chegando até as políticas constitucionais, assiste-se a uma ampliação sem precedentes (MOTTA, 2000; RODRIGUES, 2000; CAMPOFIORITO, 1985). As atribuições de valor à arquitetura moderna tiveram novos movimentos e novos sujeitos. Os recém-criados órgãos estaduais atuaram com força evidente na preservação da memória moderna. Em paralelo, novas narrativas, talvez menos hegemônicas, oriundas de novas publicações de livros e dos novos periódicos de arquitetura como as revistas Projeto e a AU, possibilitaram um aquecimento dos debates e possibilidades de veiculação do movimento moderno. Elas, como veremos mais adiante, não transformaram substancialmente as práticas de atribuição de valor, tal como estruturadas pelo Iphan até a década de 1980, no que se refere à arquitetura moderna.

Após o tombamento da Catedral de Brasília em 1967, as proteções legais feitas pelo Iphan sofrem um intervalo de pouco mais de uma década até que novos tombamentos de bens imóveis modernos aconteçam. Nos anos 1980 chegam ao Iphan vários pedidos referentes à arquitetura moderna, o que de pronto transparece a mudança do perfil de atuação nos "tempos de abertura" mais permeável às demandas da sociedade. Também são abertos outros processos pelos técnicos da instituição, como foram o do Parque Hotel São Clemente e o do Parque Guinle, de 1984 de Lucio Costa, pedidos pela Diretoria Regional do Iphan no Rio de Janeiro (IPHAN, Processo de tombamento n. 1110T-84; IPHAN, Processo de tombamento n. 1109-T-84).

Inicialmente os processos do Parque Guinle e do Parque Hotel São Clemente são negados em análise do arquiteto Edgar Jacintho, que já havia dado parecer favorável ao tombamento da Associação Brasileira de Imprensa - ABI, questionando a validade do tombamento de bens culturais contemporâneos, juízo que poderia ser feito "com mais acerto pelas gerações futuras". Sugere o equacionamento do problema por meio da criação de novo instituto jurídico do tombamento "ad referendum" com o prazo de carência correspondente a uma geração, quando seria melhor analisado (IPHAN, Processo de tombamento n. 1110T-84 e n. 1109-T-84).

O pedido é então estudado por Antônio Pedro de Alcântara, arquiteto do Iphan, que não duvida dos valores das obras de Lucio Costa, e lembra da profunda 
ligação do arquiteto com o Iphan: "(...) parece-nos chegado o momento da SPHAN e do País saldar uma dívida com seu antigo servidor, desmentindo o dito popular de que 'santo de casa não faz milagre'". (IPHAN, Processo de tombamento n. 1110-T-84) A proposta de novo tipo de reconhecimento é negada internamente, e o tombamento das obras foi indicado segundo inquestionável reconhecimento de "elementos significativos de sua obra como patrimônio nacional". Segundo Dora Alcântara, à época diretora da Divisão de Estudos e Tombamentos do Iphan, a dificuldade das obras modernas não era sua historicidade, mas a grande quantidade de obras de interesse, o que exigiria responder com critérios rigorosos. (IPHAN, Processo de tombamento n. 1110-T-84)

Tanto Dora Alcântara quanto o conselheiro Kneese de Mello foram firmes quanto ao valor histórico das obras de Lucio Costa, desprendendo-se do significado meramente arquitetônico. Para o arquiteto que vinha discutindo o tema da valoração e historicidade da arquitetura moderna no Condephaat (NASCIMENTO, 2019), não havia questionamentos quanto ao sentido "eterno e irreversível" do Parque Guinle e do Hotel de Friburgo. O arquiteto Kneese de Mello foi conselheiro responsável pelos pareceres da $A B I$, das casas de Warchavchik, das obras de Lucio Costa e de Brasília, todos favoráveis. Mostrou-se emocionado e pessoalmente envolvido com a causa, exaltando o feito dos colegas e a arquitetura nacional. A história canônica da arquitetura moderna, nos termos de Carlos Martins (1999) transparece nos pareces e nas citações a Le Corbusier, Yves Bruand e Lucio Costa, entre outros. (IPHAN, Processo de tombamento n. 1100-T-83)

O arquiteto Augusto da Silva Telles, importante dirigente da área central do Iphan desde os anos 1970 defende com ênfase o tombamento, sob o argumento de que essa já era uma prática comum na instituição (IPHAN, Processo de tombamento n. 1110-T-84). Além das dúvidas de Edgar Jacintho, o então diretor da regional do Recife, Ayrton de Carvalho, negou, em 1986, o pedido feito pelo Governador do Estado de Pernambuco de tombamento do Pavilhão de Óbitos do arquiteto Luís Nunes, sob o argumento da ausência de valor histórico e de excepcionalidade. O processo voltou a ser analisado cerca de dez anos depois, em 1997, pelo arquiteto José Simões Belmont Pessôa, contundentemente favorável à proteção legal pelo Iphan. Mostrou em seu parecer a importância da experiência de Luís Nunes à frente da Diretoria de Arquitetura e Construção, fato de ressonância nacional. Fundamentado em Bruand, para quem o Pavilhão de 
Óbitos era "obra prima", e na publicação Brazil Builds, na qual figura, José Pessôa conclui pelo tombamento imediato do bem artístico nacional como reconhecimento a um dos "melhores exemplares do primeiro momento da arquitetura moderna brasileira como a crítica já o fazia desde 1943, data da publicação de Brazil Builds". (IPHAN, Processo de tombamento n. 1206-T-86)

Sob a argumentação de valor inegável para a nação, dentro da lógica da narrativa historiográfica consagrada, estando ameaçadas ou não de descaracterização, as obras modernas entraram para os livros do tombo desde os anos 1940 e retomaram com força na década de 1980. Em uma década em que há uma ampliação sem precedentes dos agentes, sujeitos, práticas e discursos do patrimônio cultural, o olhar para a arquitetura moderna reiterou os critérios estéticos na atribuição de valor às obras (devidamente legitimado pela historiografia) e deu grande importância às autorias e individualidades arquitetônicas. A partir dos anos 1970, a entrada dos municípios e dos órgãos regionais na discussão do patrimônio, permitiu reestruturar progressivamente as possibilidades seletivas, os conceitos e critérios do patrimônio. A inclusão da arquitetura moderna no rol de bens protegidos pelos órgãos estaduais de São Paulo e Rio de Janeiro, assim como no Iphan, significou pouco em termos da renovação conceitual da década da redemocratização. A arquitetura moderna esteve no vértice do problema da ampliação conceitual ao patrimônio, tensionando as práticas estabelecidas de valoração, na medida em que os pedidos de preservação feitos pelas comunidades chegavam a partir de outros olhares ao patrimônio para muito além daquele dos especialistas.

\section{Os modernos "regionais" como patrimônio: Rio de Janeiro e São Paulo}

Os órgãos estaduais de patrimônio, de fôlego e agenda nova em face às políticas de patrimônio e das metodologias críticas propostas nos anos 1970 e, com muita força nos anos 1980, igualmente abraçaram a arquitetura moderna no seu escopo de trabalho. Inepac - Instituto Estadual do Patrimônio Cultural do Rio de Janeiro - e Condephaat - Conselho de Defesa do Patrimônio Histórico, Arqueológico, Artístico e Turístico do Estado de São Paulo - incluíram obras de arquitetura moderna nos seus livros de tombo em momento coincidente com a retomada da crítica de arquitetura via novas revistas - como a Projeto e a AU - e as muitas publicações sobre o assunto. Além disto, há uma cons- 
trução de memória do movimento moderno no Brasil que é feita diante novas práticas projetuais, mas, sobretudo, diante da percepção da passagem do tempo e de sua historicidade. A arquitetura moderna como legado começa a se organizar nos anos 1980. Que bens comporiam essa herança e que fazer com eles?

Tanto no Rio de Janeiro, quanto em São Paulo, foram mobilizadas as elaborações historiográficas da intelectualidade da arquitetura. A excepcionalidade da arquitetura e principalmente a autoria, segundo Silvia Wolff e Tony Zagato (2007; 2016), contaram nos tombamentos de edifícios modernos pelo Condephaat muito mais do que em arquiteturas de outros períodos. A vinculação das obras aos arquitetos célebres da escola paulista, assim citada, aliada às características técnico-construtivas será motivação para as proteções de muitas das obras. Mesmo que os critérios de seleção nunca tenham sido elaborados, os tombamentos atenderam a dado perfil de arquitetura moderna: aquela estabelecida pela linha de interpretação sacramentada pela história da arquitetura escrita e ensinada a serviço do projeto, com caráter operativo. As motivações e justificativas para a seleção da arquitetura moderna a preservar veio estritamente dos saberes da arquitetura, da história da arquitetura, fundada em critérios estético-estilísticos.

Dois casos nos ajudam a entender os entrelaçamentos entre historiografia e salvaguarda do patrimônio cultural moderno na década de 1980: o Cine 9 de Abril, em Volta Redonda/RJ, e a Casa Modernista, em São Paulo. Uma obra no interior do Estado, de arquiteto desconhecido pelo grande público, representante da expansão da linguagem moderna no Brasil, nos termos mostrados por Fernando Lara (2005). A outra, peça fundante da arquitetura moderna nacional, mas mergulhada nas polêmicas historiográficas da chamada "trama narrativa" da arquitetura (MARTINS, 1999). Em ambos os casos, os pedidos de preservação partiram do interesse da população, mas os crivos técnicos e historiográficos foram decisivos na construção de argumentos a favor ou contra a proteção legal.

Um dos episódios mais importantes do patrimônio no Brasil, no que se refere às mobilizações populares da primeira metade da década de 1980 foi o da Casa Modernista, em São Paulo. Às vésperas do ano novo de 1984 o então diretor do Condephaat Antônio Augusto Arantes abriu o processo de tombamento da Casa Modernista na Vila Mariana projetada por Gregori Warchavchik, naquele momento sob ameaça de 
demolição para a construção de edifícios residenciais, garantindo, assim, o seu tombamento em caráter provisório (Decreto n. 13426 de 16.3.1979, artigos 142, 144 e 146). A luta pela preservação da casa envolveu moradores do bairro, políticos, universidades e demais interessados em episódios que tiveram passeatas, confrontos com a polícia, duras argumentações com os proprietários e processos judiciais. Abaixo-assinados da comunidade e pareceres de especialistas fundamentaram o processo de tombamento aprovado pelo Conselho Consultivo do Condephaat em 1984 (RODRIGUES, 2001).

A Casa Modernista foi construída pelo arquiteto para sua família no final dos anos 1920, onde viveu por cerca de 40 anos. No final dos anos 1970 a casa ficou vazia e em 1983 os herdeiros deram início à venda para uma imobiliária. O empreendimento Palais Versailles, com quatro torres de apartamentos, ocuparia boa parte do terreno, impedindo o uso do jardim que era feito pelos moradores do bairro. Diante disso, uma intensa mobilização dos moradores do bairro da Vila Mariana e de estudiosos se iniciou para impedir a destruição da casa e salvaguardar a área verde ao redor (RODRIGUES, 2001). A proposta de preservação valorara os aspectos simbólicos ou afetivos da casa e dos jardins para a população, motivadores da luta por sua manutenção. O grupo foi organizado em torno do "Movimento Pró-preservação do Parque Modernista", que empreendeu muitos esforços para a salvaguarda da casa e jardins.

O interessante é que tanto no Condephaat, quanto no Iphan, os valores arquitetônicos justificaram a patrimonialização da casa. Preservou-se não uma casa como tantas outras da Vila Mariana, importante para o bairro e para o cotidiano dos moradores do bairro, mas a icônica Casa Modernista, exaltada por certa historiografia paulista como gênese do movimento moderno. Estes aspectos contaram decisivamente em muitos dos pareces técnicos de tombamento. No Iphan a argumentação arquitetônica é levada ao ponto de o ato de tombamento não se restringir apenas à "pioneira" casa da Vila Mariana (conforme "opinião do arquiteto Lucio Costa"), mas incluir outras duas residências do arquiteto - as casas da Rua Bahia e da Rua Itápolis - que representavam o conjunto da obra de Warchavchik e a "evolução" de sua obra. Ou seja, como a primeira casa era parte de um processo inicial e inacabado em direção à linguagem moderna, importava proteger o conjunto das obras residenciais do arquiteto, em que os ajustes foram sendo feitos em favor da suposta "verdade 
arquitetônica". (IPHAN. Processo de tombamento n. 1121-T-84, Casa modernista de Warchavchik na Rua Santa Cruz)

Como mostrou José Lira (2011), a interpretação de que a casa de Warchavchik era discrepante com o discurso do arquiteto foi repetida por vários historiadores como Carlos Lemos e Yves Bruand. Construída com alvenaria de tijolos, piso de tijolos sobre vigas de madeira e platibanda escondendo a cobertura em telhas de barro, para Bruand, a casa traía os cinco pontos da arquitetura de Le Corbusier, e por isso não era verdadeiramente moderna. As argumentações do Iphan pelo tombamento das três casas refletiam esta interpretação historiográfica. A afirmação de que o tombamento perpetuaria o tempo, evocando os valores da historiografia da arquitetura brasileira, provava as relações entre preservação e escrita da história, tecido pelo Iphan desde o tombamento do edifício do Ministério da Educação e Saúde. A proteção legal das três casas de Warchavchik integra a retomada dos estudos da arquitetura moderna pelo Iphan.

Muito diferentes foram os debates em torno da proteção jurídica de outra obra do século XX: o Cine 9 de Abril, em Volta Redonda. O pedido chegou ao Inepac - Instituto Estadual do Patrimônio Cultural do Rio de Janeiro em 1988 por iniciativa do prefeito da cidade, a partir das ameaças de fechamento e destruição pelo proprietário, o Clube dos Funcionários. A população que já se mobilizara antes pelo tombamento municipal, agora pedia a proteção estadual do edifício projetado em 1956 por arquitetos da Companhia Siderúrgica Nacional, desconhecidos pela narrativa estabelecida pela história da arquitetura até aquele momento. Os arquitetos Glauco de Couto Oliveira e Ricardo Tonumasi utilizaram-se do seu vocabulário formal, como pilotis, marquises, amplos espaços, janelas em fita e escadarias imponentes, atestando "uma apropriação popular do vocabulário modernista em voga na época da construção de Brasília", conforme o estudo do processo de tombamento. O pedido foi acolhido pelos técnicos do Inepac que viram no edifício relevância arquitetônica, mas também relevância social, pois era local importante de festas e espetáculos no Vale do Paraíba. Ademais, era remanescente dos cine-teatros das cidades do interior, o quais vinham desaparecendo velozmente. (INEPAC, Processo de tombamento $\mathrm{n}$. $\mathrm{E}-18 / 18.147 / 88)$

Na ocasião, o mesmo pedido de tombamento foi encaminhado ao Iphan. Em resposta, o edifício é detalhadamente analisado pelo arquiteto Antônio Pedro 
de Alcântara com desenhos, cortes, plantas e esquemas comparativos, afirmando ser ele "(...) fruto de um processo dialético; resultado final do confronto de estímulos e inibições que as aproximaram mais ou menos das matrizes importadas" (IPHAN, Processo de tombamento n. 1278-T-88) Apoiado na recém-promulgada Constituição Federal (1988) no seu importante artigo n. 216 referente ao patrimônio cultural brasileiro, o arquiteto apontou que não havia mais a exigência da excepcionalidade arquitetônica para se compreender o valor de um bem cultural e conclui pela colaboração do Iphan com o poder municipal na proteção do bem cultural. A dificuldade de articulação entre as instâncias governamentais de patrimônio - que se verifica com evidência até os dias de hoje - se fez presente e não houve trabalho conjunto do Iphan com a prefeitura. O processo retomou a pauta do ConseIho Consultivo em 1993, quando foi questionado pelo proprietário do edifício, o Clube de Funcionários da Companhia Siderúrgica Nacional. Os acalorados debates sobre o "valor nacional" e o "valor local" foram reveladores das disputas de saberes do patrimônio e como a entrada de novos agentes e a expansão das fronteiras territoriais e discursivas ainda iriam requerer muitos esforços para seu rompimento. Ao fim e ao cabo, o tombamento do Cine-teatro de Volta Redonda foi negado pelo Iphan e o processo arquivado. (IPHAN, Processo de tombamento n. 1278-T-88).

Como já indicado, o Inepac realizou o tombamento. O órgão, que na década de 1980 estava comprometido com a democratização do patrimônio - acolhendo os pedidos feitos pela comunidade e interessado em processos urbanos e sociais das cidades do interior do Estado do Rio de Janeiro - viu no Cine Teatro 9 de Abril e no movimento social que organizou a sua preservação, uma expressão do patrimônio que defendia (CAMPOFIORITO, 1985). E, por isso, digno de valoração patrimonial. No entanto, essa não foi regra das ações quando se olha o conjunto de ações. De modo geral as proteções legais feitas pelo Iphan e pelos órgãos estaduais Condephaat e Inepac atenderam à lógica das valorações estéticas ou estilísticas, em que obras de Lucio Costa, Irmãos Roberto, Vilanova Artigas, Oscar Niemeyer foram valorizadas. Se em alguns casos pairavam dúvidas quanto à pertinência da proteção de obras sem o devido distanciamento temporal, elas logo foram amainadas diante dos argumentos da honra e homenagem aos grandes mestres da arquitetura brasileira (NASCIMENTO, 2019). 


\section{Os anos 1990 e 2000: moderno (re) consagrado}

Entendo que a partir da década de 1990 o patrimônio moderno constituiu-se como categoria com a ampliação do interesse pela arquitetura e urbanismo modernos no Brasil e no exterior, a atuação do Iphan no tema e a criação de organizações como o Docomomo. É na década de 1990 que o tema da arquitetura moderna se institucionaliza no Iphan e que é criado o Docomomo-Brasil, sediado na Universidade Federal da Bahia. Com a realização do Seminário Internacional no Brasil em dezembro de 2000 na cidade de Brasília, estabeleceram-se redes que não pararam de se multiplicar. $O$ interesse acadêmico gerou inúmeros trabalhos monográficos sobre arquitetos, instituições, edifícios e personagens mostrando o feixe de concretizações da arquitetura brasileira no século XX. Tantos foram os trabalhos fundamentados na ideia do revisionismo crítico da historiografia da arquitetura brasileira que, como destacou Carlos Martins, passados tantos anos de referência, ele corre o risco, inclusive, de tornar-se um chavão (MARTINS, 2011).

Durante a gestão de Glauco Campello como presidente do Iphan na década de 1990 formou-se um grupo de trabalho encarregado de pesquisar a obra de Oscar Niemeyer (Portaria IPHAN n. 203/97). Diante da vastidão da sua obra em todo território nacional, fez-se um arrolamento inicial com a ajuda da Fundação Oscar Niemeyer e do Docomomo, optando-se pelo estudo progressivo sem prazos determinados de conclusão. Como resultado dos trabalhos foram abertos os processos de tombamento do CTA-Centro Tecnológico da Aeronáutica em São José dos Campos-SP e do Parque do Ibirapuera em São Paulo.

A consagração da obra de Niemeyer é fato no Iphan desde suas origens nos tombamentos da gestão de Rodrigo Melo Franco de Andrade. E perpetuou-se deste modo nos atos administrativos que se seguiram, exaltando o gênio nacional e a excepcionalidade de suas obras, cujo ato mais elucidativo é o tombamento, em 2007, de 24 obras do arquiteto em comemoração ao seu aniversário de 100 anos. A seleção das obras a serem tombadas iniciou-se a partir de listagem elaborada pelo próprio autor. A opção pelos aspectos estético-estilísticos das edificações de Niemeyer evidencia-se no tombamento do Ibirapuera que exclui o parque, tratado como entorno. A separação entre cidade e obra, entre parque e edifícios monumentaliza 
as construções e as desassocia de sua história, além de não incluir os jardins, lugar de memória da cidade de São Paulo (SCIFONI, 2006).

O incômodo com a atenção exclusiva aos grandes personagens e obras do modernismo foi externado pelo historiador da arte Marcos Tadeu Ribeiro, a propósito do tombamento do CTA - Centro Tecnológico da Aeronáutica e lembrando a negativa do conselho ao tombamento do "não-excepcional" cinema de Volta Redonda. Para o historiador a instituição deveria estudar o modernismo como amplo processo cultural de múltiplos desdobramentos e de presença em todo território nacional, não se restringindo a bens culturais de maior expressão na história da arte, e atentar para outras manifestações cuja necessidade de preservação é igualmente relevante e testemunham a abrangência nacional do modernismo, além de refletirem as suas "várias fases".

Os tombamentos da Pampulha e, sobretudo, do município de Cataguases-MG, ambos de 1995, responderam, na medida do possível, a tais indagações. A poligonal de tombamento incluiu toda a Lagoa da Pampulha e o entorno, incluindo amplas áreas dos bairros adjacentes às obras, com a sugestão da inclusão de bens no inventário do município. Em Cataguases a proposta de tombamento, feita em parceria pelas regionais do Iphan de Minas e de São Paulo, buscou contemplar o "sentimento moderno" presente na trama urbana, nos edifícios de autores consagrados, nas obras de arte e também naquilo que Antônio Luís Dias de Andrade chamou de "arquitetura moderna vernacular". Para reduzir o risco de dar sentido apenas às obras de autores consagrados, o que não abarcaria a extensão do seu legado, a poligonal de tombamento tratou o problema na sua dimensão urbanística. Entretanto, a escolha de fazer um "conjunto arquitetônico" com a somatória de algumas obras excepcionais tombadas e uma grande poligonal de entorno abarcando o que seria essa arquitetura vernacular moderna excluiu uma série de bens culturais que contavam a história urbana do lugar, como duas das vilas operárias (PEREIRA, 2016a). O "caráter inconcluso" da cidade como "lugar de modernidade" foi contemplado no conceito de centro histórico - delimitado não por um tombamento da cidade toda, mas por uma grande área de entorno (IPHAN, Processo de tombamento, $\mathrm{n}$. 1342-T-94).

Na gestão de Ítalo Campofiorito como presidente do Iphan - arquiteto que havia participado da construção de Brasília e que nos anos 1980 teve papel funda- 
mental no projeto do Corredor Cultural e na gestão do Inepac - a proposta de tombamento de Brasília foi adiante. A valoração de Brasília no Iphan teve início na gestão de Aloísio Magalhães quando se criou o Grupo de Trabalho para a Preservação de Brasília para a candidatura da cidade como Patrimônio da Humanidade. No início dos anos 1980 Brasília mobilizava os arquitetos brasileiros que tentavam haver-se com seu legado, o que pode ser visto, por exemplo, no II Inquérito Nacional de Arquitetura de 1982, em que havia uma pergunta sobre a importância de Brasília como experiência urbana (IAB-RJ, 1982). As posições variadas e extremadas indo da exaltação da obra do "mestre Lucio Costa" à negação contundente mostraram o nível de mobilização que causavam e o interesse que havia pelos personagens e obras do moderno, que seguiam povoando imaginários e pranchetas. 0 envolvimento do Iphan com a preservação da cidade foi mais uma tomada de posição do Instituto em favor da manutenção das "obras de arte" do século XX no momento em que as críticas eram abertas. O documento final do Iphan estabelece a manutenção dos gabaritos e do parcelamento e uso do solo vigentes e corrobora a sugestão de tombamento feita por Lucio Costa que, embora entenda a cidade como dinâmica, corrobora a ideia de cidade como monumento (IPHAN, Processo de tombamento, n. 1305-T-90).

Nos anos 2000, durante a Era Lula e especificamente na gestão de Gilberto Gil no Ministério da Cultura, expandiram-se os discursos e as práticas do patrimônio pelo Iphan (PISSATO, 2018; PEREIRA, 2016; FIGUEIREDO, 2014; BRANDÃO, 2020). Elas desdobraram-se na ampliação das possibilidades de proteção no Brasil, ainda que com muitos limites (MARINS, 2016; PAIVA, 2019). O tombamento em 2010 do conjunto urbano da Vila Serra do Navio no Estado do Amapá - projetado nos anos 1950 pelo arquiteto paulista Oswald Bratke para a empresa mineradora ICOMI - mostra as ambivalências do processo de expansão da agenda patrimonial do período e como a arquitetura moderna se colocou, novamente (MAGALHÃES, 2020). Ela foi ora como nova fronteira de ações para o patrimônio, ora reiteradora das antigas práticas. A proteção foi importante na consideração de espaços e lugares pouco tratados pelo Iphan até o momento, diante de clara politica de maior representação territorial das políticas de cultura e de patrimônio. Ampliar os limites do que se poderia considerar patrimônio era, de certa forma, também ampliar o escopo temporal e material do patrimônio a salvaguardar, considerando as diversidades que compunham o ideal de nação múltipla na sua composição social. Da mesma forma 
que considerar novos territórios, sobretudo em lugares pouco representados pela ação federal, era fazer do patrimônio meio possível de superação das desigualdades de toda ordem que assolam o país. Este é o caso de diversos tombamentos de sítios urbanos do período que se preocuparam com o patrimônio como vetor de desenvolvimento, do qual a Vila Serra do Navio não é exceção. Mas, o tombamento e as ações de salvaguarda estruturaram-se em um ideal de originalidade e de autenticidade de arquitetura moderna, em que os usos, adaptações e mudanças feitas ao longo do tempo pelos usuários eram disruptivos.

As promessas de atenção ao movimento moderno já haviam sido firmadas pela criação, em 2008 no Depam - Departamento do Patrimônio Material e Fiscalização do Iphan, do Grupo de Trabalho de "Acautelamento da Arquitetura Moderna", para a realização de amplos inventários regionais. A proposta de criação do grupo, firmada pelo então arquiteto da Superintendência Regional da Bahia, Nivaldo Andrade, do qual participaram diversos técnicos lotados em outros estados, era reconhecer a diversidade e a amplitude da produção da arquitetura e urbanismos modernos no Brasil, estudando sistematicamente as obras da produção moderna em todo país, contemplando sua abrangência, diversidade e formas de materialização. O estudo da arquitetura moderna no Iphan pouco avançou diante das dificuldades internas dadas pelas mudanças politicas depois de 2013. Assim como em momentos anteriores, as ações de inventário e pesquisa restaram paralisadas face às inúmeras urgências e à crônica falta de recursos materiais e humanos que assolam os órgãos de preservação. A esperança, ao menos no caso de São Paulo do qual participei como arquiteta e funcionária de carreira do Iphan, era de que a realização de um inventário sistemático pudesse incluir bens culturais fora do consagrado ou monumental e, com isso, abrir a possibilidade para retomar trabalhos, processos e intenções dos anos 1980, além de possibilitar nos crivos conceituais para a proteção da arquitetura e o urbanismo modernos.

\section{Considerações Finais}

A valoração ao movimento moderno no Iphan, acompanhada grandemente pelos órgãos estaduais como Condephaat e Inepac, tendeu à perpetuação das práticas da ortodoxia patrimonial. Ao ligar, por meio da história da arquitetura, os tempos do colonial ao do moderno, este assumia o valor de obra de arte, atemporal e digno de preservação, coerente com a opção pelo monumental e excepcional. Conscientes nos anos 
1980 da historicidade dos anos 1940 e 1950, os técnicos das instituições de patrimônio, estudiosos e conselheiros entrelaçaram narrativas da história com a do patrimônio. Os tombamentos atenderam a dado perfil de "arquitetura moderna" estabelecida pela linha de interpretação sacramentada pela história da arquitetura escrita e ensinada a serviço do projeto. A construção de memória dos grandes mestres, seguiu reiterada pelos textos canônicos, com critérios estruturados em excepcionalidade e autoria. Muitas vezes, o pragmatismo da gestão limitou as valorações, justificadas pelas reais e crônicas limitações orçamentárias e humanas de que padecem os órgãos de patrimônio.

As hesitações à proteção legal de edifícios de habitação social são didáticas dos limites impostos à expansão das fronteiras de valoração da arquitetura e do urbanismo modernos. Este é o caso exclusão das vilas operárias na poligonal de tombamento de Cataguases e da desconsideração das formas de morar tradicionais e das mudanças feitas ao longo do tempo em Vila Serra do Navio (PEREIRA, 2016a; MAGALHÃES, 2020). Ficaram evidentes as dificuldades para usar o instituto do tombamento em obras do movimento moderno de habitação social, o que pode ser visto, também, na negativa de proteção pelo Condephaat do Conjunto Residencial Zezinho Magalhães, em São Paulo (NASCIMENTO, 2019). Ou, ainda, na exclusão da área verde do Conjunto Residencial da Mooca em São Paulo do tombamento em nível municipal, área essa que foi o vetor de mobilização dos moradores em favor da preservação diante das ameaças de construção de um edifício no local. Para o Pedregulho de Affonso Eduardo Reidy e Carmen Portinho, apesar de seu inequívoco reconhecimento nacional e internacional como obra de grande relevância da arquitetura brasileira, o seu uso de habitação popular, com toda sorte de desafios históricos de salvaguarda, tem dificultado o reconhecimento federal como patrimônio nacional. O processo de tombamento encontra-se aberto desde os anos 1980, mas sem andamento, ainda que de um de seus edifícios - o serpenteante Bloco A - tenha sido restaurado em 2015.

Mas, de modo geral, limites conceituais e práticos impuseram-se frente às ampliações do patrimônio nos anos 1960 e 1970 quando o tema é salvaguarda de bens do movimento moderno. As mudanças, seja nos órgãos estaduais, seja em esfera federal, foram proximamente acompanhadas da continuidade das políticas e do pensamento patrimonial há anos estabelecido. Considerando que cumpria aos órgãos 
estaduais zelar pelos valores ditos regionais ou mais próximos às populações e comunidades, seguindo os preceitos constitucionais, nos processos que envolveram a arquitetura moderna eles nem sempre apareceram. Favoreceu-se, como regra geral, a proteção das obras excepcionais e dos grandes mestres do movimento. Em poucos casos, como no Cine 9 de Abril de Volta Redonda e na Casa Modernista de São Paulo a arquitetura moderna apropriada pela população e demandada como patrimônio oficial aos órgãos, foi preservação respeitando-se os valores afetivos ou simbólicos mobilizados pelos grupos locais. Em menor número comparecem edificações fora do escopo consagrado pela vertente corbusiana da arquitetura brasileira, como nos tombamentos dos edifícios art déco de Goiânia, do Elevador Lacerda em Salvador e dos edifícios do Estado Novo no Rio de Janeiro. A hegemonia construída pela ação inicial do Iphan foi tornada memória social, como mostra Lia Motta (2000, p. 1819), e fixou na lembrança dada imagem tradicional de patrimônio. Mesmo com tantas transformações, os arquitetos dos órgãos de patrimônio ou fora deles buscaram representar o Brasil conforme idealizado por meio da atribuição estética e de características nacionais às construções identificadas, mesmo que não fossem exatamente coloniais.

Restam, portanto, muitos desafios para pensar o que seria uma categoria de "patrimônio moderno", com práticas que considerem os bens como referências culturais, atravessados de significados múltiplos e socialmente apropriados. Para encerrar o percurso histórico feito neste artigo, cito três desafios que me parecem necessários para pensar novas e futuras ações de salvaguarda: o primeiro é o da superação do lugar do especialista como o único legítimo para a seleção de bens modernos, devendo-se incluir a participação dos usuários - no seu sentido mais amplo possível - nos processos patrimoniais. A hipótese de pouco interesse ou crítica à arquitetura moderna, que pode sustentar diversas ações no exterior, não parece ser necessariamente verdadeira para o caso nacional, o que, naturalmente não pode ser generalizado e precisaria ser melhor compreendido em situações específicas. O segundo ponto, ligado ao primeiro, seria o de superação dos impasses dos usos e transformações feitos pelos usuários como sendo deturpadores de um suposto projeto original, compreendo os termos sociais e significados históricos das mudanças e seus sentidos para o presente dos objetos e das comunidades. O terceiro e último, é constatação de um reconhecimento desigual da arquitetura moderna no Brasil, cujas seleções hierarquizam edifícios 
e espaços num quadro mais amplo de bens possíveis a salvaguardar, valorizando-se obras autorais e desconsiderando-se outras tantas cujos valores estão para muito além de uma coleção obras consagradas.

\section{Referências}

IAB-RJ/ PROJETO EDITORES. II Inquérito Nacional de Arquitetura/ Depoimentos, 1982.

INEPAC. Processo de tombamento n. E-18/18.147/88, Cine 9 de Abril.

IPHAN - Instituto do Patrimônio Histórico e Artístico Nacional. Processo de tombamento n. 1121-T-84, Casa modernista de Warchavchik na Rua Santa Cruz.

Processo de tombamento n. 0375-T-48, Edifício na rua da Imprensa, 16 (edifício-sede do Ministério da Educação e Saúde), com toda a área de terreno situada entre as ruas da Imprensa e de Santa Luzia, a avenida Graça Aranha e a rua Araujo Porto Alegre, necessária a preservação de sua perspectiva monumental (Rio de Janeiro-RJ) neiro.

Processo de tombamento n. 0375-T-48, Edifício na rua da Imprensa, 16, Rio de Ja-

Processo de tombamento Edifício conhecido como RP-1 ou "Catetinho" 0594-T-59).

Processo de tombamento n.0373-T-47, Igreja de São Francisco de Assis.

. Processo de tombamento n. 1278-T-88, Cine 9 de Abril.

. Processo de tombamento n. 1110-T-84, Conjunto Residencial do Parque Guinle. Rio de Janeiro: Iphan, 1984.

Friburgo-RJ

Processo de tombamento n. 1109-T-84, Hotel do Parque São Clemente, Nova Processo de tombamento n. 1110-T-84, Conjunto Residencial do Parque Guinle.

Friburgo-RJ.

Processo de tombamento n. 1109-T-84, Hotel do Parque São Clemente, Nova Processo de tombamento, n. 1305-T-90, Brasília: conjunto urbanístico.

Processo de tombamento n. 1100-T-83, Associação Brasileira de Imprensa.

Processo de tombamento n. 1110-T-84, Conjunto Residencial do Parque Guinle.

. Processo de tombamento n. 1206-T-86, Pavilhão Luís Nunes.

Processo de tombamento, n. 1342-T-94: Cataguases.

PROJETO. "DPH procura evitar destruição da casa da Rua Santa Cruz", Projeto, fev. 1984.

MARCO, Anita di. "DPH procura evitar destruição da casa da rua Santa Cruz", Projeto, n. 60, fev. 1984. 
ARANTES, P.F. Arquitetura Nova. Sérgio Ferro, Flávio Império e Rodrigo Lefèvre, de Artigas aos mutirões. São Paulo: Editora 34, 2004.

BRANDÃO, M. Patrimônio na agenda do desenvolvimento e o PAC-CH em São Paulo: estratégias e debates nos anos 2000. Dissertação (Mestrado em História e Fundamentos da Arquitetura) - Faculdade de Arquitetura e Urbanismo, Universidade de São Paulo, 2020.

CAMPOFIORITO, Ítalo. "Muda o mundo do patrimônio" Revista do Brasil, no 4. Rio de Janeiro: Secretaria de Estado de Ciência e Cultura, Rioarte, 1985.

CAVALCANTI, L. (org.). Modernistas da repartição. Rio de Janeiro: Iphan/ EdUFRJ, 2001.

FIGUEIREDO, V. G. B. Da tutela dos monumentos à gestão sustentável das paisagens culturais complexas: inspirações à política de preservação cultural no Brasil. Tese (Doutorado em Planejamento urbano e regional) - Faculdade de Arquitetura e Urbanismo, Universidade de São Paulo. São Paulo, 2014.

LARA, F. M Modernismo Popular: Elogio Ou Imitação? Cadernos de Arquitetura e Urbanismo, v. 12, n. 13, p. 171-184, dez. 2005.

LIRA, J. T. C. Warchavchik: fraturas da vanguarda. São Paulo: Cosac \& Naify, 2011.

MAGALHÃES, M. O. Patrimônio cultural e tecnologia social: experiências de preservação e propostas de participação para a Vila Serra do Navio/AP na Amazônia. Dissertação (Mestrado Profissional) Iphan - Instituto do Patrimônio Histórico e Artístico Nacional. Rio de Janeiro, 2020.

MARINS, P. G. Novos patrimônios, um novo Brasil? Um balanço das políticas patrimoniais federais após a década de 1980. In Estudos Históricos. v.29, n.57, p. 9-28, janeiro-abril 2016.

MARTINS, C. "Hay algo de irracional..." Block, Buenos Aires, n. 4, pp. 8-22, dez. 1999.

MARTINS, C. "Trama historiográfica e objeto moderno", Entrevista concedida a Julyane Poltronieri e Maíra Piccolotto. Desígnio, no 11/12, mar. 2011.

MOTTA, L. Patrimônio urbano e memória social: práticas discursivas e seletivas de preservação cultural, 1975 a 1990. Dissertação (Mestrado) Memória Social e Documento UniRio. Rio de Janeiro: 2000.

NASCIMENTO, F. B. "Preservando a arquitetura do século XX: o Iphan entre práticas e conceitos". Cadernos do PROARQ (UFRJ), v. 19, p. 172-193, 2013.

. Blocos de Memórias: habitação social, arquitetura moderna e patrimônio cultural. 1a. ed. São Paulo: Editora da Universidade de São Paulo / Fapesp, 2016.

- "A arquitetura moderna e o Condephaat no desafio das práticas seletivas". REVISTA CPC (USP), v. 13, p. 116-140, 2019.

PAIVA, M. C. O Brasil segundo o IPHAN: a preservação do patrimônio cultural brasileiro durante a gestão de Gilberto Gil no MinC (2003-2008). Tese (Doutorado em História e Fundamentos da Arquitetura e do Urbanismo) Faculdade de Arquitetura e Urbanismo, Universidade de São Paulo, São Paulo, 2019.

PEREIRA, D. C. "Cidade, patrimônio e território: as políticas públicas federais de seleção no Brasil do século XXI". REVISTA CPC (USP), v. 21, p. 36-70, 2016.

PEREIRA, D. C. Entre a reificação da arquitetura modernista e o apagamento da memória: 
o caso de Cataguases - MG. PARC Pesquisa em Arquitetura e Construção, 2016a, 7(1), 46-57.

PEREIRA, D. C. Cidade, patrimônio e território: as políticas públicas federais de seleção no Brasil do século XXI. REVISTA CPC (USP), v. 21, p. 36-70, 2016.

PISSATO, C. S. Tombamento e gestão em Iguape/SP: políticas do patrimônio cultural nos anos 2000. Dissertação (Mestrado em História e Fundamentos da Arquitetura e do Urbanismo) FAU USP. São Paulo: 2018.

RODRIGUES, M. Imagens do passado: a instituição do patrimônio em São Paulo, 19691987. São Paulo: Unesp / Imprensa Oficial do Estado / Condephaat / Fapesp, 2000.

RODRIGUES, C. N. Territórios do patrimônio: tombamentos e participação social em São Paulo. Dissertação (Mestrado) - Programa de Geografia Humana FFLCH USP, São Paulo, 2001.

SCIFONI, S. A construção do patrimônio natural. Tese (Doutorado) Geografia Humana FFLCH/USP. São Paulo, 2006.

WOLFF, S. "Arquitetura moderna paulista - a preservação oficial". Texto apresentado no I Seminário Docomomo Vale do Paraíba. São Paulo, mimeo, 2007.

WOLFF, S. F. S.; ZAGATO, J.A. C. "A preservação do patrimônio moderno no Estado de São Paulo pelo Condephaat". Arquitextos, São Paulo, ano 17, n. 194.07, Vitruvius, jul. 2016. 